\title{
A Conceptual Model of Individual and Collective Personality in Motion
}

\author{
Marie-Élène Roberge \\ Roosevelt University \\ Wen-Rou Huang \\ Feng Chia University
}

This paper addresses gaps in the personality literature by focusing on both levels, the individual and the collective level of personality in motion. It proposed a conceptual model that sheds lights on personality change and its underlying psychological mechanisms which explain how individual personality changes to impact the configuration of collective personality. It identifies contextual factors that affect the process of change in personality at both levels. It presents some propositions for guiding future research activities. Finally, it discusses the limitations of the proposed conceptual model and brings some insights into practical applications and future research avenues.

\section{INTRODUCTION}

Personality is defined as the relatively enduring pattern of thoughts, emotions, and behaviors that characterize a person, along with the psychological mechanisms and processes behind those characteristics. Personality is an important determinant to make people similar to or different from others about how they think, feel, and behave (Robbins \& Judge, 2017). According to the literature, personality is shaped by both nature and nurture which determine the specific type of personality of each individual. Research has also indicated that personality has been shown to influence career choice, job satisfaction, stress level, leadership, and job performance (Barrick \& Mount, 1991; Robbins \& Judge, 2017). Since personality is an important factor that accounts for what and why people act the way they do, it is a concept that has been well studied by scholars (for a review of the literature see van der Linden, Dunkel, $\&$ Petrides, 2016).

However, there are remaining gaps in the personality literature that prompt us to further pursue them in this paper. First, most research has conceptualized people's personality as being stable over time (Roberts, Walton, \& Viechtbauer, 2006; Dalal, Myer, Bradshaw, Green, Kelly, \& Zhu, 2015; Li, Barrick, Zimmerman, \& Chiaburu, 2014, McCrae \& Costa, 2003, 2008; Peeters, van Tuijl, Rutter \& Reymen, 2006) while few studies have been conducted with the assumption that personality can be changed. Specifically, personality change is defined as "change in the individual's characteristic pattern of thought, emotion, or behavior as well as change to the mechanisms behind these patterns" (Tasselli, et al., 2018, p. 468). Gendlin (1964) proposed a theory of personality change based on people's experience with their environment. He described how personality takes different forms based on people's experiences. Allport also proposed that personality changes by embracing the notion of personality flexibility. He suggested 
that "the pull of the situation is, however, so powerful that we are forced to regard personality as never a fixed entity or pattern" (Allport, 1961, p. 181). Another researcher, Walter Mischel (1968), discussed the person-situation debate and criticized the fixed trait approach to personality as inconsistent with evidence that people's behaviors tended to be determined by the pressures of different situations. Despite the fact that these researchers proposed that personality changes, in the literature "there has been neglect of the possibility that personality can change and neglect of when and how such changes occur (Tasselli, Kilduff, and Landis, 2018, p. 467). In this paper, we aim to provide theoretical answers to these research questions.

Second, while most studies have only examined individual personality, very few researchers have studied collective personality (Roberge and $\mathrm{Xu}, 2014$ ). Different from the individual personality, collective personality is described as behavioral patterns that occur within a group as a unit analysis (Hofmann \& Jones, 2005). It is the concept of applying the Big Five dimensions to the collective level. Collective personality can facilitate the development of positive or negative intragroup behaviors. When collective personality traits foster friendship, supportive social relationships, and conflict resolution, the group is more likely to develop prosocial and interpersonal citizenship behaviors. On the other hand, when collective personality shares anxious, depressive and stressful emotions, the group is more likely to generate negative working atmosphere and therefore produce counterproductive or antisocial behaviors. In the current literature, the issue of collective personality has rarely been examined and there is a lack of knowledge about the change in individual personality and its influence over collective personality. How individual personality changes to impact the emergence of collective personality must be further studied.

Drawing on these theoretical backgrounds, this paper contributes to the literature by proposing that personality changes continually over time, and by focusing on the emergence of individual and collective personality under the exposure of contextual factors. It presents a conceptual model which suggests that personality at both levels of analysis changes by interacting with contextual factors leading individuals to adopt adaptive attitudes and behaviors within a group (Fleeson 2007). The model explains the phenomena of personality change by focusing on three underlying psychological mechanisms to personality structure: 1) trait dominance and trait unexpressive, 2) trait rotation and trait permutation, and 3) the interactions of contextual factors (Mischel, 1968). According to the proposed model, some contexual factors influence change in personality by activating those underlying psychological mechanisms of personality structure at the individual personality and within the collective personality (Cervone, 2005; Tuckman, 1963). Specifically, the model explains that depending on some contextual factors, individual personality evolves in a group leading to the construction of a collective personality. It therefore describes personality in motions which explains how personality in group develops, and how it changes over time, when interacting with others, or based on the interaction with other types of contextual factors to produce adaptive attitudes and behaviors within a group (Fleeson, 2007). The paper identifies several contextual factors that play an important role in predicting the emergence of personality profiles at both individual and collective levels. These contextual factors are related to time spend with others in a group, people's past experiences, the size of the group, the composition of the group, the occurring social interactions, the content of the task to be performed, and the cultural environment. More precisely, the model suggests that these contextual factors influence the position of the traits within the individual personality and therefore the emergence of the configuration of collective personality.

To sum up, the purpose of this paper is to propose a conceptual model that examines how personality change at an individual and collective level of analysis when individuals are exposed to different contextual circumstances. This paper first describes what constitutes individual personality by relying on the Big Five model, followed by defining collective personality and personality change. A thorough explanation of the three underlying psychological mechanisms is provided to explain how personality evolves and changes to produce different configurations of collective personality. Some propositions will be stated to guide future research. Finally, the paper presents a discussion that sheds lights on several new research avenues to verify if the model could stand in organizational settings. 


\section{LITERATURE REVIEW}

\section{Big Five Model}

Personality refers to the sum total of ways in which an individual reacts and interacts with others (George \& Jones, 1998). Individual personality has enduring characteristics that describe an individual's attitudes and patterns of behaviors. It is a unique set of characteristics, or traits, that define an individual personality and determine that person's pattern of behavioral interactions with the environment. It is the bundle of characterisitcs that allow people to show individual differences. Individual personality is contituted of five major traits as those previously described by the Big Five model.

The Big Five model has been proposed in 1992 by Coasta and McCrae. It is composed of five broad dimensions representing most personality traits that constitute the traits of personality within each individual: Openness to experience, Conscientiousness, Extraversion, Agreeableness and Neuroticism. Openness to experience refers to being imaginative, artistic, sensitive, nonconforming and intellectual. Conscientiousness refers to being goal-focused, responsible, dependable, persistent, and organized. Extroversion refers to being outgoing, sociable, gregarious, and assertive. Agreeableness refers to being tolerant, flexible, good-natured, cooperative, and trusting. Neuroticism refers to calm, self-confident, secure (positive), versus anxious, depressed, and insecure (negative). This model assumes that personality is stable over time. To be more specifically, it suggests that personality becomes more stable by adulthood. Rarely, the Big Five model has been used to postulate movement within personality (Tasselli, Kilduff, \& Landis, 2018).

However, recent empirical research has also indicated that personality develops and changes mainly from childhood to young adulthood, typically stabilizing by around age of thirty (see McShane \& Glinow, 2018). Indeed, some scholars have reported that the personality traits of openness to experience and social vitality increase through to young adulthood and decline after age thirty, and other traits such as agreeableness and conscientiousness tend to increase through to later life (McShane \& Glinow, 2018). Roberts, Caspi and Moffitt (2001) had claimed that the personality changes that did take place from adolescence to adulthood reflected growth in the direction of greater maturity.

\section{Collective Personality}

Collective personality is defined as group personality and refers to the behavioral regularities manifest at a unit level, as a whole (Hofmann \& Jones, 2005; Roberge, Xu and Rousseau, 2014). In other words, collective personality describes the routines occurring within the collective personality as a whole and produces regularized, consistent patterns of behaviors that can be observed and described by others, the same applies to individual personality. Thus, the construct of collective personality provides insights into underlying psychological processes that can affect the effectiveness of a unit, group, team or organization. At the organizational level, collective personality has been characterized as "recurring patterns of behavior of multiple organizational members involved in performing organizational tasks" (Feldman \& Rafaeli, 2002, p. 311). At the group level, it represents "informal rules that groups adopt to regulate and regularize group member behavior" (Feldman, 1984, p. 47). Note that, these collective norms and routines can not only be transmitted to new members of the collective but also continue even after the original members of the collective leave (Barker, Wyatt, Johnson, Stone, O'Bryant, Poe, \& Kent 1993; Morgeson \& Hofmann, 1999; Weick, 1979). For example, the transmission of norms and routines to new members should result in some changes and adaptative behaviors, but then lead to some consistencies over time, even as the different subgroups come together to work at any given point in time within the unit.

\section{Personality Change}

While personality is defined as "the relatively enduring pattern of thoughts, emotions, and behaviors that characterize a person along with the psychological processes behind those characteristics", personality change is defined as "change in the individual's characteristic pattern of thought, emotion, or behavior as well as change to the mechanisms behind these patterns" (Tasselli, et al., 2018, p. 468). 
Theoretically, personality is shaped by both nature and nurture. Nature refers to generic or hereditary origins in which the genes that inherit from the parents, whereas nurture refers to the socialization, life experiences and other forms of interactions with the environment (Robbins \& Judge, 2017).

The nurture part of personality is stimulated and developed through growth background, family interactions and educational environment, interactions with people, either positive or negative life experiences, and experienced successes or failures. Following on this line of reasoning, social learning theory proposes that people's personality changes based on social observations and interpersonal interactions. According to this theory, people learn new behaviors by observing other persons whom they believe are credible and knowledgeable (Noe, 2010). It also recognizes that people's behaviors are reinforced or rewarded which lead them to be repeated. Thus, when people are in a group, they have the opportunity to learn from each other through communication and interpersonal interactions in such a way that they readjust their own behavior and modify their own thoughts and emotions to adapt to or join the group.

Our model proposes that personality change occurs via social learning processes at the individual and group levels of personality. The change takes place when the underlying psychological mechanisms of personality structure are activated (Cervone, 2005; Tuckman, 1963). Those mechanisms regulate the process of change within both levels of personality. These psychological mechanisms are trait dominance and trait unexpressive, and trait rotation and permutation of traits. Once they are activated from interacting with contextual factors, they predict how individual personality changes to impact the emergence of collective personality. These mechanisms are further explained in the following sections.

\section{THEORETICAL MODEL AND PROPOSITIONS}

\section{Dominance and Unexpressive Traits Predicting Individual and Collective Personality}

To predict the individual and collective personality, we present a theoretical model that incorporates the five traits of the Big Five model and assumes that these traits are interdependent as shown in Figure 1. The model proposes that when people get together as a group, they move in their psyche as the interact with others, the task, the time and the environment. As mentioned earlier, based on social learning theory, people learn from each other through social observations and interpersonal interactions. Thus, this interactional effect between the traits and these contextual factors influence how people feel, think and behave towards others and how they react to and interact with other members of the group they belong to (Fleeson, 2007). Through the interaction and learning process, some traits of individual personality become more or less salient which defines dominancy or unexpressive of the personality traits. These traits rotate their position around a disk to adapt to the demanding factors within a group. As a result, it adjusts, changes and re-defines people's thoughts, feelings and behaviors to be able to be accepted by all group members and to renew into a collective personality.

Specifically, according to the model, the effects of five traits of the Big Five model are in constant motion, they become more or less pronounced to predict individual personality, and as a result, to shape the configuration of a collective personality. In the figures presented, the dominating traits of personality are highlighted in yellow and the unexpressive traits of personality are reminded in white. The emergence of a collective personality is driven by the activation of the psychological mechanism of the dominancy versus unexpressive of the individual personality traits. As illustrated on figure 1, the dominant traits overlap with the sphere of collective personality which therefore determine its configuration. While the dominant traits of individual personality have direct effects over the configuration of collective personality, the unexpressive traits of individual personality have indirect effects over the collective personality.

Therefore, the dominant and unexpressive individual traits of personality predict the emergence of collective personality and its effects on people's attitudes and behaviors within the group. However, the change process of personality is also determined by the process of traits rotation and permutation of the dominating versus unexpressive traits. 


\section{FIGURE 1 \\ CONCEPTUAL MODEL ILLUSTRATING THE DOMINANCY AND UNEXPRESSIVE TRAITS OF INDIVIDUAL PERSONALITY MOVING TO CREATE A CONFIGURATION OF A COLLECTIVE PERSONALITY COMPOSED OF TEN INDIVIDUALS}
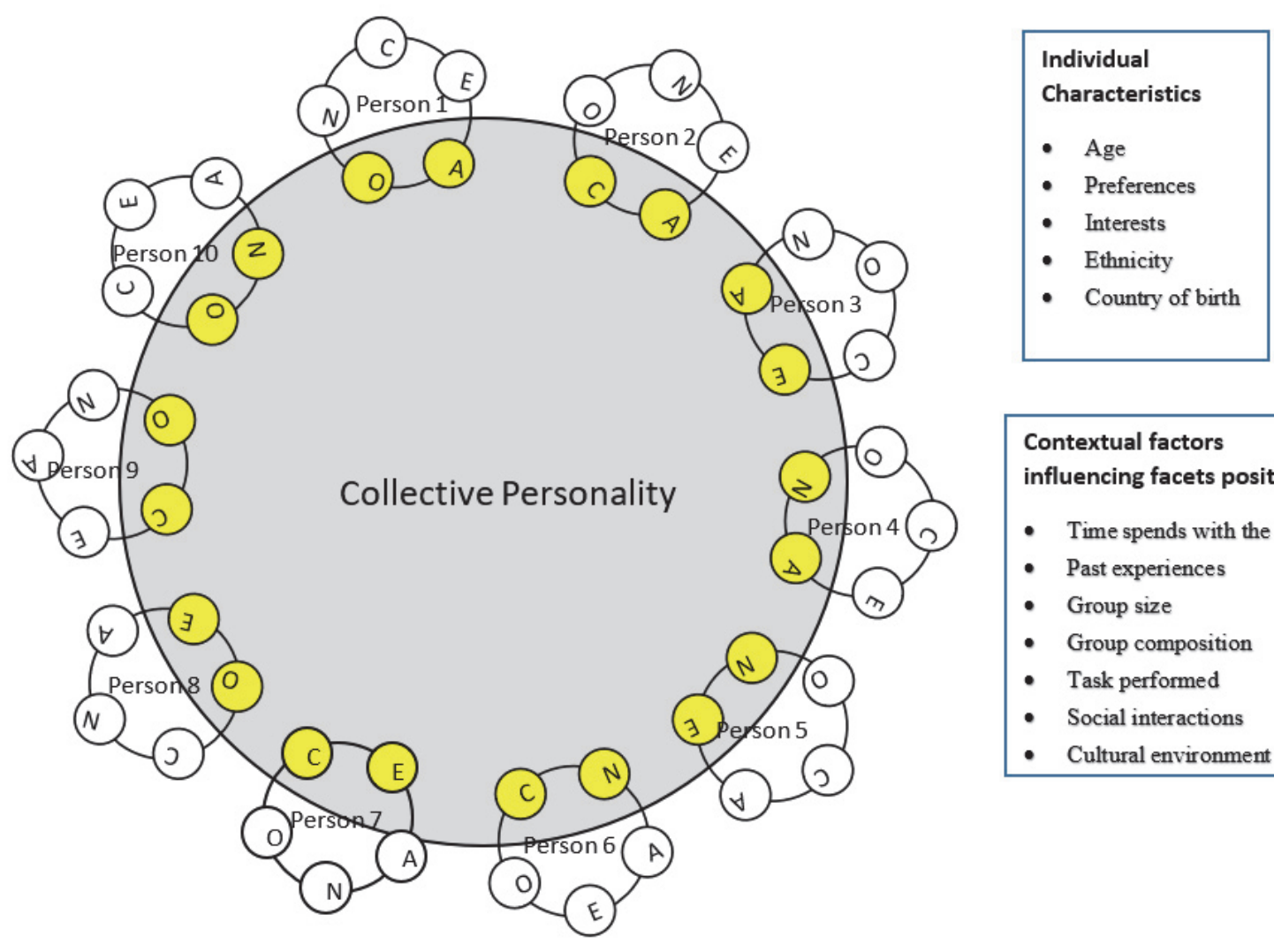

Contextual factors influencing facets position

- Time spends with the group

- Past experiences

- Group size

- Group composition

- Task performed

- Social interactions

- Cultural environment

\section{Rotation and Permutation Process of the Traits Predicting Individual and Collective Personality}

All groups change over time as group members interact with one another, and as they join or leave the group. The dynamist of a group changes as the interpersonal relationships evolve within the group as well as with the contextual factors. According to Tuckman's five-stage model (1963), for a group to function well, the group members must spend time interacting with each other to know and to establish a common understanding, to deal with the conflicts encountered, and then to develop a close feeling of friendship with one another (George \& Jones, 1998). In other words, the development of the group is a changeable and dynamic process within which personality, at both levels, evolves.

While group members composed of different personalities get together to achieve certain goals, their individual personalities will affect their individual behaviors and then interact with and learn from each other to create a collective atmosphere within the group. Thus, the theoretical assumption behind the proposed model is that the facets of personality are diverse and dynamic at both individual and collective levels of personality and that the individual traits, based on the big five theory, switch position to interface collective personality and produce appropriate behaviors within the group in different situations. Specifically, the model proposes that the five traits of individual personality are in a constant motion and rotate around a disk with permutations. These traits interact with one another within the individual personality and the position of the traits move in a way that produces adaptive attitudes and behaviors to the demanding situational factors. Once the traits have taken place into their position, the individual traits of personality influence the emergence of the configuration of collective personality. Both, the individual personality and the collective personality are always reaching out for stability as the interpersonal 
interactions evolve with time. However, they never reach complete stability since people within a group are in a constant interaction.

For example, in Figure 2, it illustrates a situation where four people are asked to remember past experiences, either remembering stressful moments in their life as opposed to remembering joyful moments of their life. Research has shown that high neuroticism and low conscientiousness predicted higher stressor exposure, dysfunctional coping and lower problem-focused coping (Grant \& Langan-Fox, 2006). Thus, in the first condition, the memory of stressful events may emphasize the dominancy of neuroticism and conscientiousness. These traits become dominant within the individual personality and will then rotates to overlap with the sphere of the collective personality, leading to produce a specific personality configuration where stress level experienced may be high. In this first condition, openness to experience, agreeableness and extraversion will stay in the unexpressive position for most people within the group since people may not feel comfortable to talk about challenging time of the life with other people they just met.

It was found that low neuroticism with high extraversion and high conscientiousness predicted lower stressor exposure and job dissatisfaction (Grant \& Langan-Fox, 2006). In addition, there had a significant positive association with happiness, optimism, positive affect, agreeableness, extroversion, and conscientiousness. (Neff, Rude \& Kirkpatrick, 2006). Therefore, when these same four people are asked to remember joyful moments of their life, in that second condition, the traits of agreeableness, extroversion and conscientiousness may become dominant for the individual personality and then rotate in a position that interfaces with the sphere of collective personality. While the dominating traits will inter-laps with the sphere of collective personality, the unexpressive traits will not and therefore will only have indirect effects over the configuration of collective personality. The dominating traits will have stronger influences over the prediction of both the individual and the collective personality. In that example, people in the first condition will be more likely to experience anxiety with one another, and have less feelings of extraversion, agreeableness and openness to experience due to the situational demand. They will have more difficulty to trust one another and to engage in prosocial behavior toward one another rather than when peoples are in the second condition remembering joyful moments of their life. The proposition is as followed:

Proposition 1: When asked to remember stressful time of their life, the individual traits of neuroticism will become dominant and rotate to define the configuration of collective personality, as opposed to when people are asked to remember joyful moments of their life, agreeableness, extroversion and conscientiousness will become dominant and rotate to define the configuration of collective personality. More trust and comfortable feelings with others, as well as more prosocial behaviors within the group will be displayed when people are remembering joyful moments, rather than when they are remembering stressful moments. 


\section{FIGURE 2 \\ EXAMPLE OF DIFFERENT PERSONALITY CONFIGURATIONS DEPENDING ON THE TYPES OF EXPERIENCES ASKED TO BE REMEMBERED}

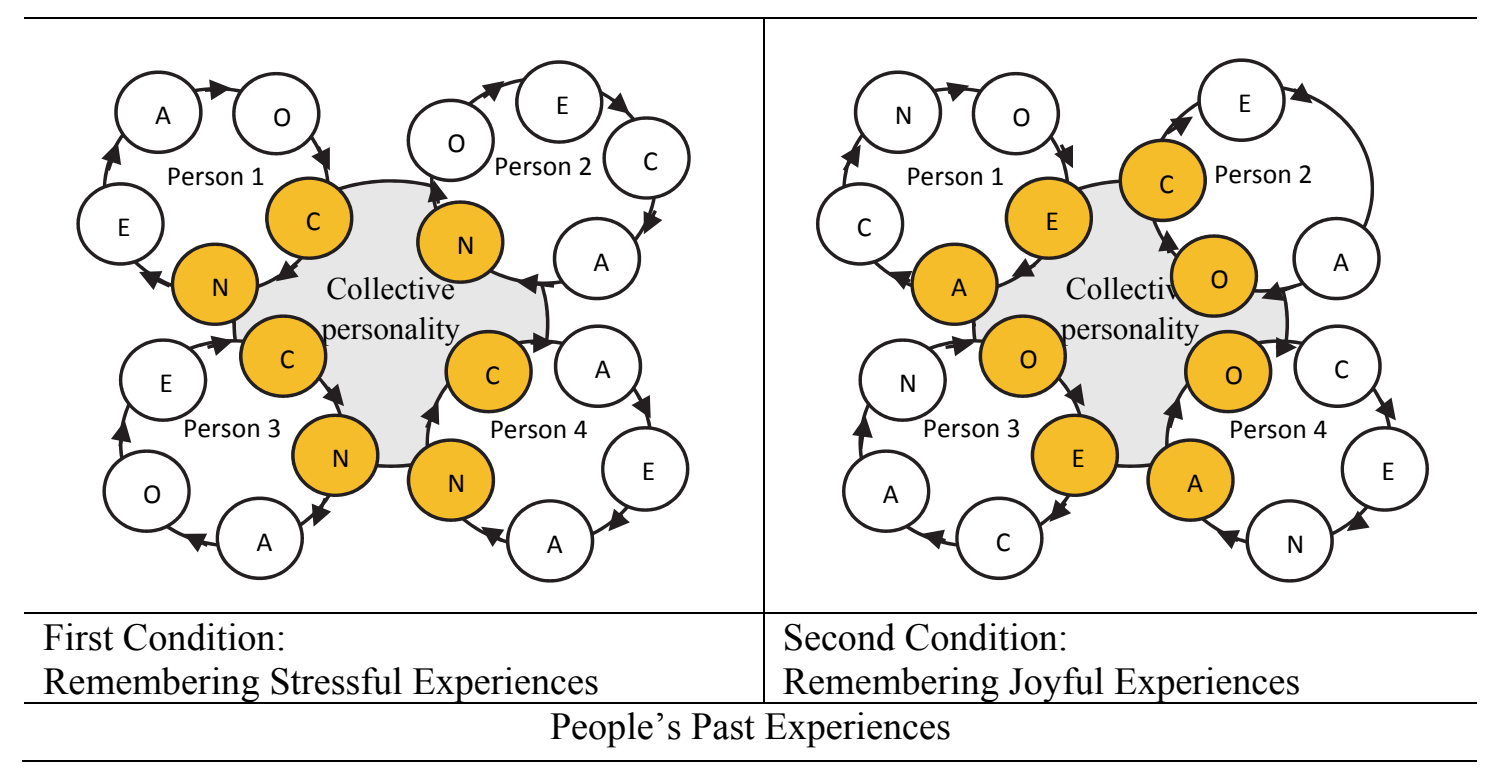

\section{Interactional Effects of Contextual Factors Predicting Individual and Collective Personality}

Remembering past experiences is only one of the contextual factors that have influence over personality at an individual level and group level. The model proposes that personality is very sensitive to the interactional effects of contextual factors such as time of measurement, time spend with group members, past experiences, group size, group composition, social interactions, the content of the task to be performed, and the cultural environment. These factors play an interactional role in determining the emergence of individual personality and the configuration of collective personality. These contextual factors influence the position of the traits of personality. When people interact with their environment, contextual factors can produce changes in personality by affecting the activation of the underlying psychological mechanisms of personality structure (i.e., trait rotation, permutation, and its trait dominance or unexpressive). These mechanisms explain how change occurs within the individual and collective personality. According to the model, the interactions between those factors impact the construction of each individual personality and, in turn, the configuration of collective personality. It is the interactional effects between contextual factors that activate the psychological mechanisms and then predict the emergence of different configurations of individual and collective personality.

The example illustrated by Figure 3 in relation with the size of the group, proposes that when the group becomes bigger, people from that group may experience social pressure which may lead them to not feel comfortable to take a chance to express themselves freely within the group. As a result, people's traits of conscientiousness, extraversion and openness to experience may move outside of the sphere of the collective personality, while other traits may take over such as neuroticism, and agreeableness (Diener, Lusk, DeFour, \& Flax, 1980). Whereas, when the group becomes smaller, the dynamic of the group changes due to the motion of the individual traits. People may feel more comfortable to express themselves freely and may be more likely to take a chance to speak up during the group interaction which then relates to display extraversion and openness to experience instead of neuroticism and agreeableness. Therefore, we hypothesized as follow: 
Proposition 2: In the first condition, when the group is large, extraversion and conscientiousness, openness to experience will rotate and stay unexpressive traits while the other traits (i.e, neuroticism and agreeableness) will rotate and dominate the configuration of collective personality. However, in the second condition, when the group is small, extraversion will rotate and become dominant along with openness to experience and agreeableness, while the other traits (i.e., neuroticism and conscientiousness) will rotate and remain unexpressive. As a result, people from the second condition will display more expressive and altruistic attitudes and prosocial behavior than people from a larger group.

Note that, another contextual factor that may interact with personality to predict the emergence of collective personality is the composition of the group, and especially the personality type of people from that group. For example, since low neuroticism with high extraversion and high conscientiousness predicted lower stressor exposure (Grant \& Langan-Fox, 2006), people characterized with these personality traits may feel good about themselves and about the world around them, they may feel excited to know and interact with other people in the group and may experience more positive emotional states compared to those individuals who do not share those traits, no matter the size of the group. Under this circumstance, the trait of extraversion, openness to experience and conscientiousness will become dominant to define the configuration of collective personality. Therefore, we propose as followed:

Proposition 3: The composition of the group related to individuals' personality type may impact the underlying psychological mechanisms that explain the emergence of collective personality.

Thus, the model proposes that the five traits of personality are consistently in rotative motion, on a rotative alternans with permutation, and that they are always influenced by the contextual factors they are exposed to. Especially, traits of the individual personality rotate to produce adaptive attitudes and behaviors within a group which then lead to the emergence of collective personality that predicts group behaviors.

\section{FIGURE 3 \\ EXAMPLE OF DIFFERENT PERSONALITY CONFIGURATIONS DEPENDING ON THE SIZE OF THE GROUP}

See figure 1.
First Condition:
Group Composed of Ten Members
The Size of the Group
Group Composed of Four Members

The example illustrated by Figure 4 is in relation with the time of measurement and the task characteristics that must be performed by the group. In a team composed of four individuals, the 
configuration of each individual and group personality become different depending on the time of measurement of personality, and the types of task the group must perform. In this example, the interaction between the time of measurement and the type of task that must be performed leads to different types of configurations of collective personality. Different individual traits of personality emerge to dominate the collective personality based on the time of measurement and the task performed.

Assuming that group members have similar job attitudes before engaging in the task, at time one, when the group members just received the task assignments, for both types of task (cognitive versus social) to be performed, people should display mainly conscientiousness and openness to experience. This is because research suggests that there is a highly positive relationship between conscientiousness and job performance (Barrick, \& Mount, 1991; Li, Barrick, Zimmerman, \& Chiaburu, 2014). In addition, people with high openness to experience tend to resolve issues by finding creative solutions. That is, they are prompt to put organized efforts into the task and are looking forward to performing the task by finding solutions. At time two, once the task has been performed, the configuration of people's personality, individual and collective, differs based on the type of task that was performed. When the task is cognitive, conscientiousness and openness to experience remind the primary dominant traits of personality that define the individual and collective personality. However, when the task is social in nature, people's personality tends to change in a way that agreeableness and extraversion become the dominant traits of individual personality and the configuration of collective personality. People in that condition, where they need to perform a social task, tend to display more expressive attitudes and altruism, as well as more prosocial behaviors than when they are in the condition where they need to perform a cognitive task. The following proposition is therefore proposed:

Proposition 4: Assuming that group members have similar job attitudes, depending on the time of measurement of personality (i.e., personality collected before and after the task performed) and the types of tasks to be performed (cognitive versus social), there will be different emergent configurations of individual and thus collective personality to adapt to the contextual demand. The personality trait displayed prior to the task to be performed does not differ. However, the measures taken once the task is performed show differences; When people perform a social task, they are more likely to display agreeableness and extraversion, whereas when people perform a cognitive task they are more likely to display conscientiousness and openness to experiences. People will display more altruism attitudes and prosocial behavior in the condition where the task is social in nature as opposed to when the task is cognitive in nature. 


\section{FIGURE 4 \\ EXAMPLE OF THE INTERACTION BETWEEN CONTEXTUAL FACTORS TIME OF MEASUREMENT AND THE NATURE OF THE TASK TO BE PERFORMED}

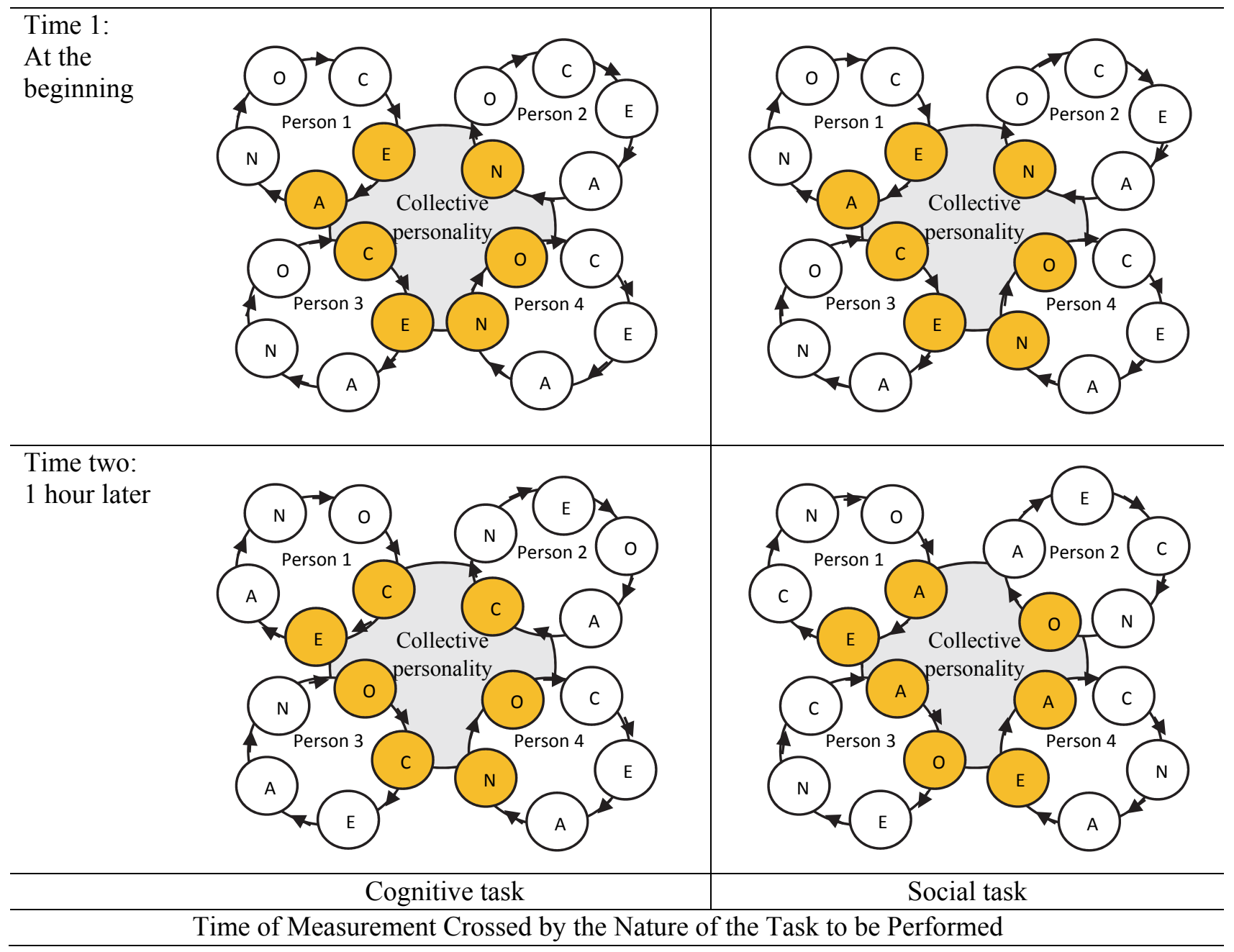

\section{DISCUSSION}

The proposed conceptual model has brought to our attention the possibility to understand personality from a different perspective that previous literature has discussed. Instead of focusing only on individual personality, this model sheds lights into how individual and collective personality change when responding to some conceptual factors. It presents the idea that it is via the process of change, based on the activation of underlying psychological mechanisms that individual personality is in constant motion affecting the configuration of collective personality. These underlying psychological mechanisms are dominant and unexpressive traits, as well as traits rotation and traits permutation, and they are activated based on some pressure from contextual factors. The interaction of the contextual factors on personality structure is addressed and figures are drawn to illustrate the process of change influenced by the interaction of several contextual factors.

This theoretical model contributes to the literature by bringing a new perspective on the personality literature. Instead of considering personality as a stable concept, it proposes that personality, individual and collective level of personality, are in constant motion to produce adaptive attitudes and behaviors within a group. Thus, individual personality influences the configuration of collective personality via 
dominant versus unexpressive traits as well as via traits rotation and permutation. Such conceptualization has never been proposed in previous personality literature and can provide guidance for further research studies.

For example, it would be interesting to verify the limitations of this model by testing it into the laboratory setting and the organizational environment. Future empirical studies should consider collecting longitudinal data to show whether this model can stand as it is in different contextual settings. Potentially other factors such as individual characteristics (i.e., age, preferences, interests, ethnicity, country of birth) could be added to the model to bring more complexity and a thorough understanding of the phenomenon of personality change and the emergence of both individual and collective personality. For instance, in organization it could be possible to collect personality data to measure it at the beginning of the employment term, during the employee selection process, and then measure personality again along with prosocial behaviors during the employment term, also call performance measure. In doing so, the model could be verified and adjusted based on the results found.

From a practical stand point, this conceptual model can help managers to understand how personality may change over time and to be more sensitive to the contextual factors that affect individual personality and the emergence of the collective personality. In today's world, most organizations operate by working with social groups, teams, or social networks and understanding the emergence of the configuration of collective personality may become an asset to manage those groups. For example, by knowing about the interactions of the contextual factors on the determination of individual personality and collective personality, managers might become able to better control for those contextual factors and better manage people's attitudes and behaviors in organizations. The model suggests another application in organization related to career development, as personality change, people may appreciate to have new opportunities in the workplace. For example, an option would be by providing employees with job rotation and learning from different aspect of the work and of the organizations. As proposed by Church, Fleck, Foster, Levin, Lopez, \& Rotolo, (2016), personality measure may be relevant to help managers to better manage career development and other functions of human resource management.

\section{CONCLUSION}

This paper sheds lights onto a theoretical model of personality in motion at the individual and group level of analyses. It suggests that individual personality changes based on the interaction with contextual factors that shape the configuration of collective personality. The activation of several underlying psychological mechanisms (i.e., trait dominance and trait unexpressive, trait rotation and trait permutation) explains the changing process of personality at both levels of personality. The model proposes that some contextual factors affect the activation of these mechanisms which determine the traits of individual personality and then enhance the likelihood for collective personality to take different forms. Very few researchers have examined these possibilities of a personality in motion at both levels and therefore, this paper contributes to bring new research avenues and practical applications in organizations.

\section{AUTOBIOGRAPHIES}

Dr. Marie-Élène Roberge is currently an Adjunct Faculty at Walter E. Heller College of Business at Roosevelt University, United States. She earned, in 2007, a Ph.D. in Labor and Human Resource Management from Fisher College of Business at The Ohio State University. She also earned a Master in Industrial and Organizational Psychology from University of Quebec in Montreal. Her research is about managing diversity and inclusion in organizations, and understanding individual and group behaviors in the workplace. She also researches on personality, training and development, and organizational justice. She can be reached at mroberge@roosevelt.edu.

Dr. Wen-Rou Huang received her MA in Workforce Development and Education from College of Education and MLHR in Labor and Human Resources Management from Fisher College of Business at The Ohio State University in 1998 and 2000, respectively. She further received her Ph.D. degree in 
Workforce Development and Education from College of Education at The Ohio State University in 2009. After joining Feng Chia University in 2010, she is currently an Associate Professor of the Department of Business Administration.. Her expertise is about human resource management, human resource development, training, recruiting and selection. She also researches on training effectiveness, training methods, self-efficacy and personality.

\section{REFERENCES}

Allport, G. W. (1961). Pattern and growth in personality. New York, NY: Holt, Rinehart, \& Winston. Barker, M., Wyatt, T. J., Johnson, R. L., Stone, M. H., O’Bryant, H. S., Poe, C., \& Kent, M. (1993). Performance factors, psychological assessment, physical characteristics, and football playing ability. The Journal of Strength and Conditioning Research, 7, 224-233.

Barrick, M.R., \& Mount, M. K. (1991). The Big Five personality dimension and job performance: A meta-analysis. Personnel Psychology, 44, 1-26.

Cervone, D. (2005). Personality architecture: Within-person structures and processes. Annual Review of Psychology, 56, 423-452.

Church, A. H., Fleck, C. R., Foster, G. C., Levin, R. C., Lopez, F. J., \& Rotolo, C. T. (2016). Does purpose matter? The stability of personality assessments in organizational development and talent management applications over time. Journal of Applied Behavioral Science, 52, 1-32.

Coasta, P. T., \& McCrae, R. R. (1992). Normal personality assessment in clinical practice: The NEO Personality Inventory. Psychological Assessment, 4, 5-13.

Dalal, R. S., Meyer, R. D., Bradshaw, R. P., Green, J. P., Kelly, E. D., \& Zhu, M. (2015). Personality strength and situational influences on behavior: A conceptual review and research agenda. Journal of Management, 41, 261-287.

Diener, E., Lusk, R., DeFour, D., \& Flax, R. (1980). Deindividuation: Effects of group size, density, number of observers, and group member similarity on self-consciousness and disinhibited behavior. Journal of Personality and Social Psychology, 39(3), 449-459.

Feldman, D. C. (1984). The development and enforcement of group norms. Academy of Management Review, 9, 47-53.

Feldman, M. S., \& Rafaeli, A. (2002). Organizational routines as sources of connections and understandings. Journal of Management Studies, 39, 309-331.

Fleeson, W. (2007). Situation-based contingencies underlying trait-content manifestation in behaviors. Journal of Personality, 75(4), 825-862.

Gendlin, E. T. (1964). A Theory of Personality Change. Personality Change. P.Worchel \& D. Byrn (Eds.), New York: John Wiley \& Sons.

Grant, S. \& Langan-Fox, J. (2006). Occupational stress, coping and strain: The combined interactive effect of the Big Five trains. Personality and Individual Differences, 41, 719-932.

Hofmann, D. A., \& Jones, L. M. (2005). Leadership, collective personality, and performance. Journal of Applied Psychology, 90, 509-522.

Li, N., Barrick, M. R., Zimmerman, R. D., \& Chiaburu, D. S. (2014). Retaining the productive employee: The role of personality. Academy of Management Annals, 8, 347-395.

McCrae, R. R., \& Costa, P. T. (2003). Personality in adulthood: A five-factor theory perspective. New York, NY: Guilford Press.

McCrae, R. R., \& Costa, P. T. (2008). Empirical and theoretical status of the five-factor model of personality traits. In G. Boyle, G. Matthews \& D. H. Saklofske (Eds.), The SAGE handbook of personality theory and assessment: 273-294. Thousand Oaks, CA: Sage.

Mischel, W. 1968. Personality and assessment. London, UK: John Wiley \& Sons.

Morgeson, F. P., \& Hofmann, D. A. (1999). The structure and function of collective constructs: Implications for multilevel research and theory development. Academy of Management Review, $24,249-265$.

142 Journal of Organizational Psychology Vol. 19(2) 2019 
Neff, K. D., Rude, S. S., \& Kirkpatrick, K. L. (2006). An examination of self-compassion in relation to positive psychological functioning and personality traits. Journal of Research in Personality, 41, 908-916.

Noe, R. (2010). Employee Training and Development. McGraw-Hill Companies, Inc., 1221 Avenue of the Americas, New York, NY 10020.

Peeters, M. A. G., van Tuijl, H. F. J. M., Rutte, C. G., \& Reyman, I. M. M. J. (2006). Personality and Team Performance: A Meta-Analysis. European Journal of Personality, 20, 377-396.

Robbins, S. P., \& Judge, T. A. (2017). Organizational Behavior Student Value Edition, $17^{\text {th }}$ Edition.

Roberge, M.É., Xu, Q. J., \& Rousseau, D. M. (2012). Collective personality effects on group interpersonal citizenship behavior: Do diverse groups benefit more? Small Group Research, 43, 410-492.

Roberts, B. W., Walton, K. E., \& Viechtbauer, W. (2006). Patterns of mean-level change in personality traits across the life course: A meta-analysis of longitudinal studies. Psychological Bulletin, 132, $1-25$.

Tasselli, S., Kilduff, M., \& Landis, B. (2018). Personality change: Implications for organizational behavior. Academy of Management Annals, 12, 467-493.

Tuckman, B. W. (1963). Personality structure, group composition and group functioning. Dissertation from Princeton University, Department of Psychology.

van der Linden, D. Dunkel C. S., \& Petrides, K. V. (2016). The general factor of personality (GFP) as social effectiveness: Review of the literature. Personality and Individual Differences, 101, 98105.

Weick, K. E. (1979). The social psychology or organizing (2 ${ }^{\text {nd }}$ ed.). Reading. MA: Addison-Wesley. 